\title{
Program Perhitungan Upah Tenaga Kerja padaProyek Konstruksi menggunakan Bahasa Pemograman Visual Basic.Net
}

\author{
Meri Sufina \\ Universitas Putra Indonesia YPTK Padang \\ E-mail: merrysulvina@yahoo.co.id
}

\begin{abstract}
Abstrak
Computer technology enters all fields including civil engineering. There have been many computer applications in civil engineering such as AutoCAD, Google Sketcup, SAP 2000, ETABS, etc. Utilization of computer technology can help various activities, one of them is construction project work. Many things cause delays in construction work, one of which is the problem of paying workers. Calculation of labor wages that still manually cause delays in payment of wages. Then a program for calculating labor wages in construction projects was made to support the construction project. This program uses visual basic.NET programming language by collecting data, designing programs and followed by making program codes to produce the desired construction wage calculation program.
\end{abstract}

Keyword: the construction project's wage calculation program

\section{Pendahuluan}

Pada saat ini perkembangan teknologi semakin luas, salah satunya komputer yang memegang peranan yang sangat penting dalam perkembangan teknologi. Perkembangan teknologi komputer dapat membantu pekerjaan manusia agar lebih mudah dan cepat. Perkembangan teknologi komputer tidak hanya sebatas dipakai untuk mesin ketik tapi juga pemanfaatan hardware, software dan brainware (pengguna) sehingga menghasilkan program komputer yang lebih bermanfaat untuk membantu pekerjaan manusia. Perkembangan teknologi komputer merambah kesemua bidang ilmu, salah satunya teknik sipil. Sudah banyak aplikasi komputer yang membantu perkembangan ilmu sipil seperti AutoCAD, Google Sketcup, SAP 2000, ETABS, dsb.

Pemanfaatan teknologi komputer dapat membantu dalam berbagai kegiatan, salah satunya kegiatan proyek pembangunan. Banyak sekali hal-hal yang dapat menimbulkan kerugian dalam proyek pembangunan, salah satunya pembayaran upah pekerja. Dalam suatu proyek kadang perhitungan upah biasanya secara manual saja tanpa adanya komputerisasi, sehingga dapat menimbulkan kecurangan yang dapat merugikan perusahaan tersebut. Contoh yang biasa terjadi diproyek adalah adanya nama tukang tidak ada orangnya alias nama tukang hantu. Atau jumlah tukang yang tidak sesuai dengan jumlah dilapangan, atau absen palsu. Ini biasa terjadi untuk proyek skala besar yang jumlah tukangya ratusan.

Masalah perhitungan gaji yang sering menjadi keributan dilapangan sehingga memunculkan masalah penyelesaian proyek yang sering terlambat karena tukang yang berhenti bekerja karena tidak dibayar gajinya sementara pihak perusahan merasa sudah membayar. Ini terjadi karena tidak ada keselarasan informasi sehingga memunculkan pertikaian. Untuk proyek skala besar yang jumlah tenaga nya ratusan ini sangat tidak terkontrol sehingga dapat merugikan perusahaan yang menjalankan proyek tersebut. Untuk itu penulis ingin mencoba membuat aplikasi perhitungan upah tenaga kerja pada proyek pembangunan menggunakan bahasa pemograman Visual Basic.NET. Sehingga diharapkan aplikasi ini dapat membatu perusahaan dalam perhitungan gaji upah tenaga kerja dalam suatu proyek bagi perusahan yang membutuhkannya. 


\section{Civil Enginerering Conlaboration}

Vol. 6 No. 1 April 2021 HAL D-16

elSSN: 2615-5915

\section{Tinjauan Literatur}

\subsection{Program}

Program komputer atau yang biasa disebut program adalah kumpulan perintah untuk melaksanakan tugas khusus dari penggunanya. Program dapat dipakai untuk melakukan tugas- tugas yang berkaitan dengan kegiatan manusia. Dengan adanya program yang dibuat dapat memberikan kemudahankemudahan diberbagai kegiatan manusia.

\subsection{Visual Basic.NET}

Visual basic. NET merupakan saah satu bahasa pemograman yang memungkinkan untuk membuat aplikasi yang berbasis windows dengan sangat mudah. Visual basic. NET adalah sebuah alat untuk mengembangkan dan membangun aplikasi yang bergerak diatas sistem .NET Framework, dengan menggunakan bahasa BASIC. Dalam Visual Basic, pembuatan aplikasi dimulai dengan memperkirakan kebutuhan, merancang tampilan dan selanjutnya diikuti dengan pembuatan kode untuk program tersebut. Visual basic merupakan sebuah bahasa pemograman yang berisi perintahperintah atau instruksi yang dimengerti oleh komputer untuk melakukan tugas-tugas tertentu.

\subsection{Upah Tenaga Kerja Proyek Konstruksi}

Didalam ketentuan umum undang-undang ketenaga kerjaan Upah merupakan hak pekerja yang diterima dan dinyatakan dalam bentuk uang sebagai imbalan dari pengusaha kepada pekerja atas suatu pekerjaan atau jasa yang telah atau akan dilakukan, ditetapkan, dan dibayarkan menurut suatu perjanjian kerja, kesepakatan atau peraturan perundang-undangan termasuk tunjangan bagi pekerja dan keluarganya. Upah Biasanya diberikan kepada pekerja yang melakukan pekerjaan kasar dan lebih banyak mengandalkan kekuatan fisik. Jumlah pembayaran upah biasanya diberikan secara harian atau berdasarkan unit pekerjaan yang diselesaikan.

Proyek konstruksi merupakan suatu kegiatan dalam melaksanakan pekerjaan teknik sipil, baik itu jalan, gedung, jembatan, irigasi, dsb. Dalam suatu proyek memiliki jangka waktu terbatas sesuai dengan pekerjaan yang ditetapkan serta dana yang di anggarkan. Untuk mengejar target penyelesaian pekerjaan kontraktor sebagai pelaksana proyek menyusun metode pelaksanaan pekerjaan. Mulai dari penyediaan bahan, pematangan lokasi, sampai kepada jumlah tenaga kerja yang dibutuhkan.

\section{Metodologi}

Metodologi dalam program ini adalah :

\section{Pengumpulan data}

Dalam teknik pengumpulan data, diinput dulu berapa data keahlian untuk upah dalam sutau proyek. Misalnya untuk proyek bendung atau jalan yang butuh alat berat maka dibutuhkan tenaga operator dengan kelas tersebut. Berbeda lagi dengan proyek gedung yang membutuhkan keahlian tukang seperti biasa. Jadi dalam pengumpulan data ini menginput dulu apa-apa saja data keahlian yang dibutuhkan kemudian disejajarkan nantinya dengan upah perharinya.

Upah yang diterima pekerja dihitung berdasarkan jumlah hari kerja dan juga ditambahkan dengan jumlah hari lembur dalam suatu proyek. Besarnya nilai upah tenaga kerja disusun berdasarkan keahlian/ kelas bidangnya. Besarnya nilai upah yang diterima pekerja tergantung kepada standar analisa harga satuan upah dan bahan yang dikeluarkan oleh Dinas Pekerjaan Umum masing-masing daerah pertriwulannya. Berikut contoh daftar upah yang diterima tenaga kerja dalam suatu proyek.

Table 1: Daftar Upah Tenaga Kerja Proyek

\begin{tabular}{clccr}
\hline NO & UPAH / TENAGA & SATUAN & HARGA SATUAN \\
1 & Pekerja & Hari & Rp & 85.000 \\
2 & Mandor & Hari & Rp & 130.000
\end{tabular}




\section{Civil Engineering Coulaboration}

Vol. 6 No. 1 April 2021 HAL D-16

elSSN: 2615-5915

\begin{tabular}{clllr}
\hline 3 & Tukang Kayu & Hari & $\mathrm{Rp}$ & 120.000 \\
4 & Tukang Batu & Hari & $\mathrm{Rp}$ & 120.000 \\
5 & Tukang Cat & Hari & $\mathrm{Rp}$ & 120.000 \\
6 & Tukang Besi & Hari & $\mathrm{Rp}$ & 120.000 \\
7 & Tukang Pipa & Hari & $\mathrm{Rp}$ & 120.000 \\
8 & Tukang Las & Hari & $\mathrm{Rp}$ & 120.000 \\
9 & Tukang Listrik & Hari & $\mathrm{Rp}$ & 120.000 \\
10 & Kepala Tukang & Hari & $\mathrm{Rp}$ & 130.000 \\
11 & Operator & Hari & $\mathrm{Rp}$ & 160.000 \\
12 & Pembantu Operator & Hari & $\mathrm{Rp}$ & 140.000 \\
13 & Penjaga malam & Hari & $\mathrm{Rp}$ & 85.000 \\
\hline
\end{tabular}

2. Desain Program

Setelah proses pengumpulan data upah pekerja, berikutnya adalah mendesain program. Data yang telah didapatkan disusun kedalam program. Kemudiam dibuatkan rumus perhitungan upah tenaga kerja proyek berdasarkan harga satuan upah pekerja perbidangnya. Desain dibuat dalam kode program perangkat lunak yang menghasilkan desain sesuai dengan program komputer yang diinginkan.

Dalam desain program perhitungan upah tenaga kerja dihitung berdasarkan jumlah hari kerja dikalikan dengan harga satuan upah berdasarkan klasifikasi keahlian pekerja tersebut(tabel 1). Dalam program dirancang lah progam perhitungan tersebut dengan menginputkan data upah pekerja berdasarkan harga satuan tersebut. Kemudian di kalikan dengan jumlah hari kerja tukang tersebut.

3. Pengujian

Setelah pembuatan desain, kemudian program dijalankan. Akan ada pengujian ulang untuk mendapatkan program yang benar. Hal ini dilakukan untuk mendapatkan keluaran yang sempurna sesuai dengan hasil yang diinginkan.

\section{Hasil dan Pembahasan}

Berikut tampilan program perhitungan upah tenaga kerja konstruksi:

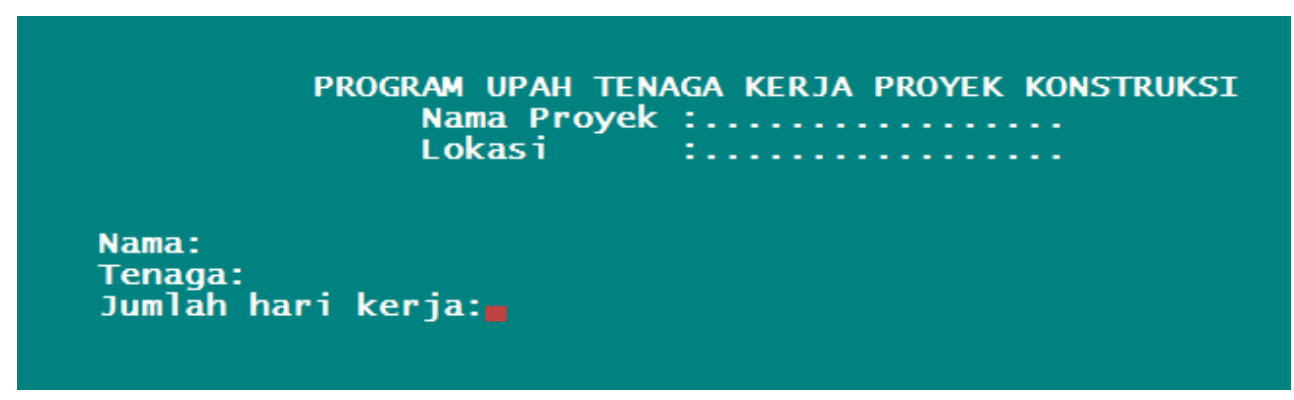

Gambar 1. Tampilan pengisian data

Dalam program perhitungan upah tenaga kerja, pertama dilakukan dulu isian data nama, tenaga/ keahlian, dan jumlah hari kerja. 


\section{Civil Engineering Coulaboration}

Vol. 6 No. 1 April 2021 HAL D-16

elSSN: 2615-5915

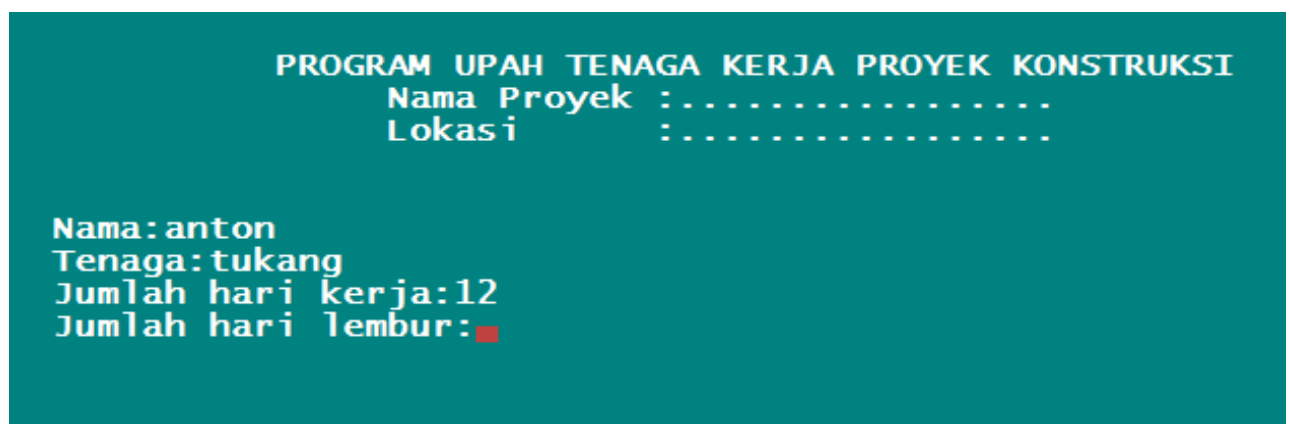

Gambar 2. Langkah pengisian data upah tenaga

Kemudian apabila masih banyak data dapat diinputkan berikutnya

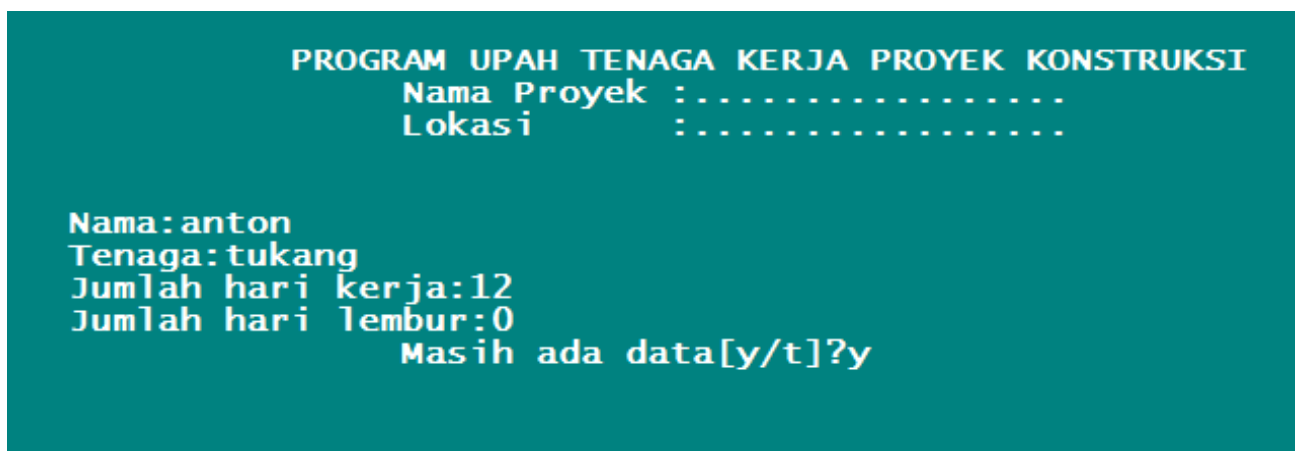

Gambar 3. Langkah pengisian data berikutnya

Dan terakhir jika tidak ada data lagi maka akan berakhir dengan rekapitulasi data. Rekapitulasi data sesuai dengan nama pekerja, keahlianya, dan hasil perhitungan upah yang diterima berdasarkan jumlah hari kerja perkerja tersebut. Berikut hasil program perhitungan pembayaran upah tenaga kerja proyek konstruksi.

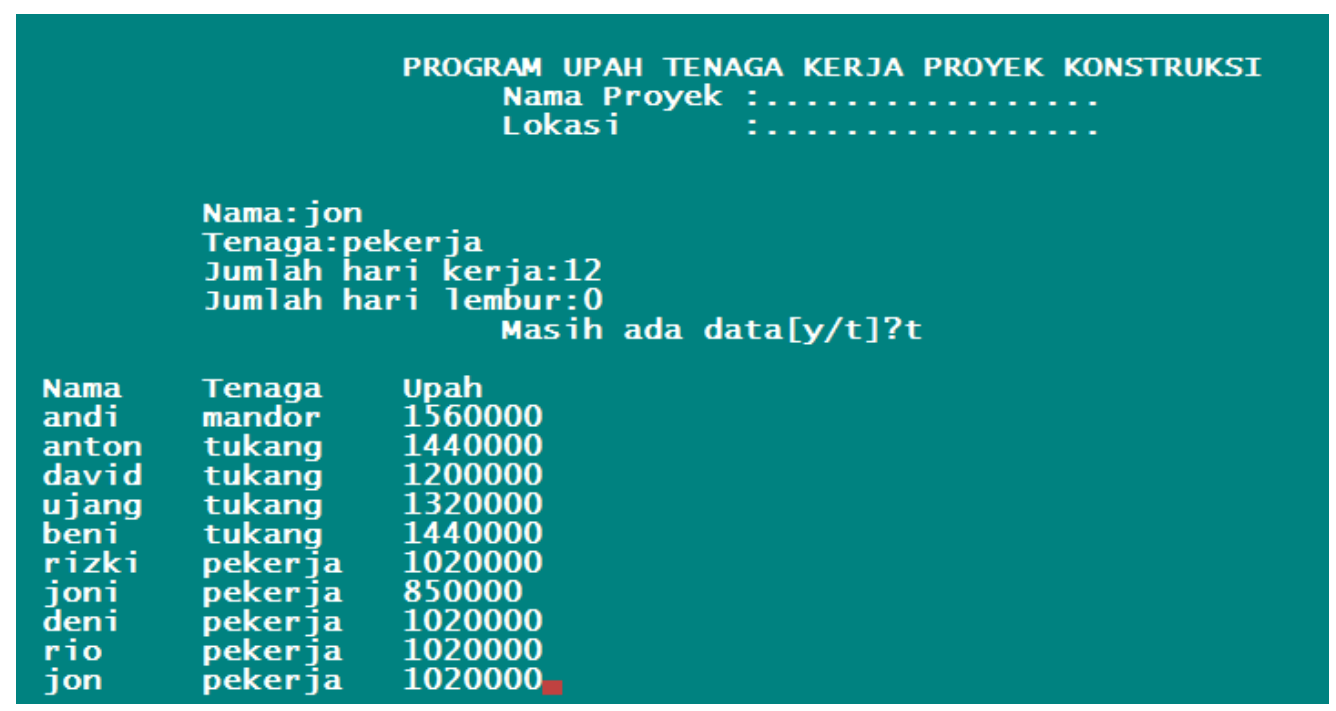

Gambar 4. Rekapitulasi perhitungan upah tenaga kerja 


\section{Kesimpulan}

Berdasarkan analisis yang telah dilakukan maka dapat ditarik kesimpulan Program ini dapat membantu lanjarnya jalan proyek dengan mempermudah dalamperhitungan gaji upah. Program ini dapat membantu dalam membuat laporan berupa absen, kasbon, dan gaji proyek agar dapat diterima tepat waktu. Program ini dapat dipakai oleh perusahan-perusahan kontraktor yang menjalankan proyek sehingga dapat meningkatkan permofmance perusahaanya. Program ini masih banyak memiliki kekurangan dan masih dapat dikembangkan ke yang lebih baik lagi.

\section{Daftar Pustaka}

[1] Konixbam. (2009). Aplikasi Dekstop Menggunakan VB. Net, Surabaya.

[2] Rifa'atunnisa., Satria, E. dan Cahyana, R., (2014). "Pengembangan Aplikasi Zakat Berbasis Android Menggunakan Metode Prototype”. Jurnal Algoritma Sekolah Tinggi Teknologi Garut. ISSN : 2302- 7339 Vol. 11 No. 12014.

[3] Sopiah, N., (2012). "Penggunaan Metode Analisis dan Rancangan Berorientasi Objek Pada Web Jurnal Ilmiah Terpadu”. Seminar Nasional Informatika 2014 (SemnasIF 2014). ISSN : 1979-2328.

[4] Sulistyorini, P., (2009). "Pemodelan Visual dengan Menggunakan UML dan Rational Rose." Jurnal Teknologi Informasi DINAMIK. Volume XIV. No. 1. Januari 2009. ISSN : 08549524.

[5] Vitrya, A. N., Tresnawati, D. dan Satria, E., (2015). "Pengembangan Aplikasi Pembelajaran Iqra' dan Tajwid Berdasarkan Metode Asy-Syafi'i Menggunakan Sistem Multimedia.” Jurnal Algoritma. Vol. 12. No. 1. ISSN : 2302-7339. 